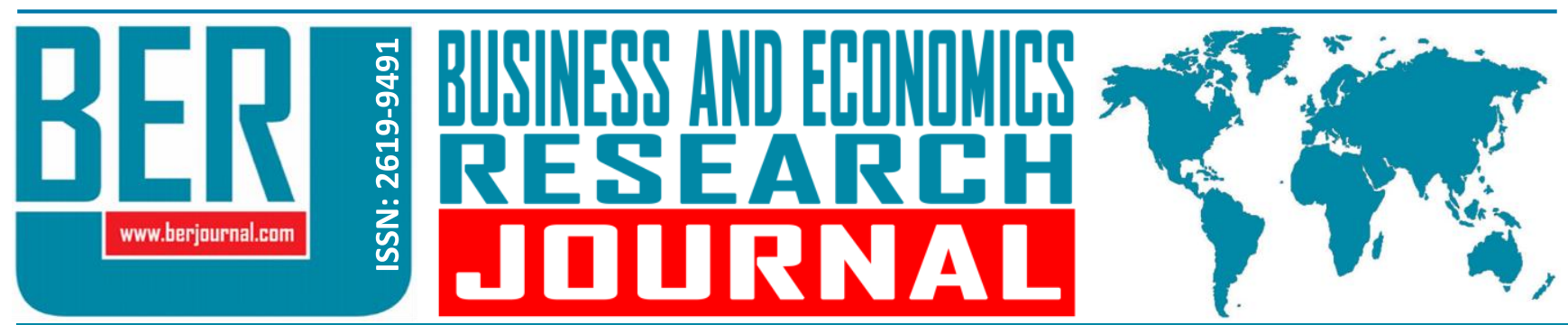

Business and Economics Research Journal Vol. 10, No. 5, 2019, pp. 1071-1084 doi: 10.20409/berj.2019.222

\title{
Measuring Systemic Risks in the Turkish Banking Sector ${ }^{1}$
}

\author{
Serkan Sengul ${ }^{\mathrm{a}}$, Ensar Yilmaz $^{\mathrm{b}}$
}

Abstract: This paper focused on measuring the systemic risks in Turkey's banking sector by using two major measures that have been proposed in the literature as conditional value at risk (COVaR) and marginal expected shortfall (MES). In order to compute the contribution of banking sector to systemic risks, the MES and $\triangle$ CoVaR measures are estimated for the six Turkish banks, which are listed, on the Borsa Istanbul (BIST) during 2000-2016 period by using Engle's dynamic conditional correlation model. The preliminary results of this study show that although the measures provide different rankings for the systemic risk contributions, they turn out to be qualitatively very similar in explaining the cross-sectional differences in systemic risk contributions. Secondly, both systemic risk measures (MES and $\triangle$ CoVaR) are analyzed to determine the relationships between some variables associated with bank characteristics (e.g., VaR, size and leverage ratio) and banks' systemic risk contributions, via simple panel data regression methods.
Keywords: Systemic Risk, DCC (Dynamic Conditional Correlation) Model, MES (Marginal Expected Shortfall), CoVaR (Conditional Value at Risk)

JEL: C23, G21, G28

$\begin{array}{ll}\text { Received } & : 27 \text { May } 2019 \\ \text { Revised } & : 26 \text { July } 2019 \\ \text { Accepted } & : 20 \text { August } 2019\end{array}$

Type : Research

\section{Introduction}

Over the past three decades, the common effects of computerisation, globalization and deregulation have given rise to a substantial structural transformation in financial sector. Banks have become financial corporations during the financialization era and focused on profitable investment banking activities. As indicated by Seccareccia (2012: 278), banks layered their assets by trading in securities, taking part in crossborder arbitrage, and relaxing credit terms for the household segment to take on a growing debt load on a scale that has not been seen heretofore. However, especially after the 2008 crisis, the question of whether there is an association between the structural changes in banking system and the systemic risks during the financialization era appear more on the agenda.

Within an increasingly complex financial system, governance mechanisms appear to become more erratic and quicker fix in which regulations are persistently trying to come up with the newly created market risks. As Ciro (2012: 216) claims, that the global financial market is interlinked with the financial markets of every other country. The overall effectiveness of systemic risk regulation will necessarily involve cooperation and coordination from other international regulatory authorities. The continuous monitoring of risk is important, because financial innovation has demonstrated that changes in systemic risk can happen quite suddenly and unexpectedly. In order to comprehensively prevent systemic risks in the financial markets, Claessens and Kodres (2014: 22) recommend financial authorities to restructure current approach to financial

a PhD. Student, Yildiz Technical University, Institute of Social Sciences, Department of Economics, Istanbul, Turkiye, sengulserkan77@gmail.com (ORCID ID: 0000-0001-9891-9477)

b Prof., PhD., Yildiz Technical University, Faculty of Economics and Administrative Sciences, Department of Economics, Istanbul, Turkiye, enyilmaz@yildiz.edu.tr (ORCID ID: 0000-0003-0870-1445) 
regulations in a truly accurate, ample and harmonized perspective. The aim of minimizing systemic risks and disruptions in financial markets is through the establishment of international regulatory authorities and regulatory frameworks.

Systemic risks can be managed and controlled not only by the independent efforts of financial institutions but also by the efforts of the financial system as a whole. So, as indicated by Tian (2017: 103) in order to understand systemic risks, it is necessary to examine both micro and macro level. The potential spread of systemic risk throughout the financial system served to highlight the limitations and challenges associated with the regulatory framework. The focus of regulations to manage and prevent systemic risk or to promote financial stability may help financial markets to protect themselves from vulnerabilities against any sudden downturns. Thus, there is an increasing trend towards the development and use of monitoring indicators for systemic risk by financial institutions.

This paper focused on measuring the impacts of regulations on the systemic risks in Turkey's banking sector by using two major measures that have been proposed in the literature as conditional value at risk (CoVaR) and marginal expected shortfall (MES). In order to measure the contribution of banking sector to systemic risks, the quarterly MES and $\triangle \mathrm{CoV}$ aR measures are estimated for the six Turkish banks, which are listed, on the Borsa Istanbul (BIST) during 2000-2016 period.

Unlike previous studies, we do not only focus on the measuring systemic risks, our testing strategy is more specific, since it is based on Turkish financial institutions. Second, in that sense, it is not only about measuring systemic risk, but also about determining the determinants of the risk. In this context, it is the only research, which is done for Turkish banking sector. Third, this paper connected the systemic risk contribution with the banking regulations, which especially are effectuated after different economic or financial crises periods.

\section{Literature Review}

The financial crisis in 2008 has led to a significant increase in the number of researches on systemic risk either on its definition, regulation or measurement. According to Reavis (2012: 3 ), the results of the crisis show that although financial institutions are well managed and supervised, the results of the crisis show that systemic risks cannot be identified and cause biodiversity in the financial system. Since then, there is an increasing effort to identify, measure and monitor systemic risks through better information and analytic models that focused on macro-prudential policies.

However, Cihak et al. (2012: 7) argue that these efforts have not sufficed yet. They claim that a standpoint that allows much more clear understanding to the market failures, interactions and externalities are still required. Further, this perspective should comprise but not just be limited to comprehensive stress tests, public financial stability reviews and other similar analyses. Claessens and Kodres (2014: 10) comment about the indicated analyses and reviews that should be an essential part of a wider course by which all supervisory entities consider their roles predominantly to oversee the financial system as a whole, and then the other financial agents within certain markets. In this way, if required micro-prudential supervisors might be able to address, for the potential systemic impacts of the individual institutions.

More specifically, Seibt and Schwarz (2011: 105) pointed out a specific source of fear associated with the high interdependency of the different financial market segments and players that have an extensive effect on the stability of the overall financial system. Such a fear is mainly identified by Bullard et al. (2009: 407) as the "systemic risk" in relation to financial institutions and markets. They also identifies the potential risk of an economic downturn such as a collapse of one financial agent or the sudden collapse of a certain market diffusing the whole financial system distressing other markets or institutions as a result of their multifaceted inherent financial interdependencies which is also called as "domino effect".

Systemic risk is defined by Stöhr (2015: 74) as a risk that can potentially create volatility in majority of the financial system. Once systemic risks occur, individual firms also experience significant difficulties to shelter themselves against its negative consequences. 
According to Guntay and Kupiec (2014: 2), due to a large loss in operational level and in turn its impacts on stock returns of individual firms in the financial system the main variables of the systemic risk mechanism are driven by at least one of the SIFIs' distress In other words, the spread of a SIFI's distress throughout the overall economy is likely to shift towards the contraction of credit channels into the real sector. In order to address this issue, Wagner (2010) claims that, although the costs of distress is reduced towards diversification, in point of fact it increases the prospect of systemic risk. This approach has been supported by the recent empirical studies such as a shift from traditional banking activities is found to increase the market risks and volatility of firms by Stiroh and Rumble (2006) and Stiroh (2006. Moreover, the diversification of financial institutions led to a higher systemic risk in financial markets in simulated models proposed by De Jonghe (2010). Therefore, the costs of diversification in financial institutions more than outweigh the benefits and can be seen as one of the factors increasing the systemic risks.

Besides the issues related with diversification, the absolute downward pressure has seen in the financial equity prices around the world which refers to a run on bank capital encompasses another element that aggregating the distress on the system. Talaslı (2013:26) indicates that the immense amounts of equity sales in financials are likely to cause bank runs. In such periods of stress and uncertainty, the general contagion in stocks may occur without distinction and possibly affect in a way that investors lose their in all segments of the entire financial system. This suggests us that there is not a significant difference between insolvent and solvent parties in the entire system. Particularly, the work of Talaslı maintains that in the short run, the institutions that are not directly influenced by these liquidity problems are also affected by the stress. Therefore, market capitalizations of most financial institutions may fall, and they encounter difficulties to raise funds in equity markets. This explains the definition of systemic risks proposed by Mishkin (1995) as the "prospect of an unexpected, usually unforeseen event that interrupts flow of information in financial markets, causing them to be incapable of efficiently allocate resources to those parties with most productive investment opportunities".

Huang et al. (2017) use the CoVaR, the MES, the SII, and VI portfolio models in order to measure systemic risk in the Chinese banking system. The study indicated that Chines banks have higher CoVaR but lower MES. These results show that Chinese banks are riskier and they are more capable to avoid losses from banking system distress. Therefore, Derbali and Hallara (2015) use the MES approach to examine systemic risk in the euro area banking system. The study explores the existence of systemic risk I the banking systems. The study ranged from January 2006 to December 2012. They discovered that after the outbreak of the financial crisis in 2007 and after the outbreak of the sovereign debt crisis in 2010 there were systematic events in European banking systems. Correspondingly, referring to MES, they did a ranking of different financial institutions.

\section{Methodology}

\subsection{Marginal Expected Shortfall (MES)}

The measures of MES are computed on the basis of the model proposed by Brownlees and Engle (2012). This model is used in order to measure each bank' the contribution to overall systemic risk. Brownlees and Engle (2012) applied the bivariate GARCH process to measure demeaned returns as follows:

$r_{t}=H_{t}^{1 / 2} v_{t}$ where $r_{t}^{\prime}=\left(r_{m, t} r_{i, t}\right)$ signifies the firm returns and vector of market where the random vector $v_{t}^{\prime}=\left(\varepsilon_{m, t} \eta_{i, t}\right)$ is i.i.d. ${ }^{2}$ and has the following first moments: $\mathrm{E}\left(v_{t}\right)=0$ and $E\left(v_{t} v_{t}^{\prime}\right)=I_{2}$, a two-bytwo identity matrix. The $H_{t}$ matrix signifies the covariance matrix and conditional variance:

$$
H_{t}=\left(\begin{array}{cc}
\sigma_{m, t}^{2} & \sigma_{i, t} \sigma_{m, t} \rho_{i, t} \\
\sigma_{i, t} \sigma_{m, t} \rho_{i, t} & \sigma_{i, t}^{2}
\end{array}\right)
$$

Where and $\rho_{i, t}$ represents the conditional correlation and $\sigma_{i, t}$ and $\sigma_{m, t}$ the conditional standard deviations. It is simply supposed that the time-varying conditional correlations completely seize the 
dependency between market and the firm returns. Properly, this postulation infers that the unvarying innovations $\varepsilon_{m, t}$ and $\eta_{i, t}$ are independently distributed at time t.

The MES at date $t$ is identified by Brownlees and Engle (2012) as;

$$
M E S_{i, t}(C)=E_{t-1}\left[r_{i, t} \mid r_{m, t}<C\right]
$$

Where $r_{i, t}$ and $r_{m, t}$ specify the market index return (e.g., BIST 100 index returns) and respectively an individual bank i's equity returns at date $t, C$ is a threshold value to denote the systemic event and, like in Brownlees and Engle (2012), set to $-2 \%$.

Let us contemplate the Cholesky decomposition of the variance-covariance matrix $H_{t}$ :

$$
H_{t}^{1 / 2}=\left(\begin{array}{cc}
\sigma_{m, t} & 0 \\
\sigma_{i, t} \rho_{i, t} & \sigma_{i, t} \sqrt{1-\rho_{i, t}^{2}}
\end{array}\right)
$$

In order to measure the MES, the Dynamic Conditional Correlation (DCC) model proposed by Engle (2002) will be employed. The conditional refers to both an individual bank's and the market's equity returns which are examined in AR (1) processes represented by $\mu_{m, t}$ and $\mu_{i, t}$, respectively. Actually in terms of conditional mean dynamics (e.g., ARMA $(p, q)$ models) more complex models could be adopted however due to the significance of modelling the conditional volatility dynamics in an accurate manner, conditional mean modelling has attached a second-order effect. Moreover, a more refined model may lead to an issue of data snooping bias. With regard to these, the conditional mean specification was planned to estimate via the simple AR (1) model. The AR (1) process is also used by Girardi and Ergun (2013) for modelling conditional mean dynamics. In a more simplified approach, any conditional mean dynamics model is not used by Brownlees and Engle (2012). The residuals filtered by the AR(1) models will be used for estimation of the univariate GARCH models hence the bivariate process of the an individual bank and the market is formulated as follows:

$$
\begin{aligned}
& r_{m, t}=\sigma_{m, t} \varepsilon_{m, t} \\
& r_{i, t}=\sigma_{i, t} \varepsilon_{i, t}=\sigma_{i, t} \rho_{i, t} \varepsilon_{m, t}+\sigma_{i, t} \sqrt{1-\rho_{i, t}^{2}} \eta_{i, t}
\end{aligned}
$$

A threshold GARCH model by Glosten et al. (1993), will be adopted for the individual GARCH processes, to find out the negative relationship between equity returns and the volatilities. More specifically, the conditional volatility dynamics are indicated by

$$
\begin{aligned}
& \sigma_{m, t}^{2}=\omega_{m}+\alpha_{m} r_{m, t-1}^{2}+\gamma_{m} r_{m, t-1}^{2} I_{m, t-1}+\beta_{m} \sigma_{m, t-1}^{2} \\
& \sigma_{i, t}^{2}=\omega_{i}+\alpha_{i} r_{i, t-1}^{2}+\gamma_{i} r_{i, t-1}^{2} I_{i, t-1}+\beta_{i} \sigma_{i, t-1}^{2}
\end{aligned}
$$

Where $I_{m, t}$ is an indicator function that has a value of 1 if $r_{m, t}<0$, and $I_{i, t}$ is formulated in the same means. The key focus in this connotation is its ability to seize the so-called leverage effect ( $\gamma$ coefficient) which is the propensity to volatility which increases further by the negative news rather than positive ones. QML is used for estimating this model to ensure providing viable and accurate parameters and to properly achieve the exact conditional variance equation.

Engle (2002)'s DCC approach is employed by modelling the time-varying conditional correlations:

The Variance covariance matrix $\Sigma$ is formulated as follows: 


$$
\sum_{t}=D_{i, t} P_{i, t} D_{i, t}=\left[\begin{array}{cc}
\sigma_{i, t} & 0 \\
0 & \sigma_{m, t}
\end{array}\right]\left[\begin{array}{cc}
1 & \rho_{i, t} \\
\rho_{i, t} & 1
\end{array}\right]\left[\begin{array}{cc}
\sigma_{i, t} & 0 \\
0 & \sigma_{m, t}
\end{array}\right]
$$

There is a so-called pseudo-correlation matrix $Q_{i, t}$ introduced by the standard DCC framework and postulates a positive definite matrix, such as

$$
P_{i, t}=\left[\begin{array}{cc}
1 & \rho_{i, t} \\
\rho_{i, t} & 1
\end{array}\right]=\operatorname{diag}\left(Q_{i, t}\right)^{-1 / 2} Q_{i, t} \operatorname{diag}\left(Q_{i, t}\right)^{-1 / 2}
$$

Here $Q_{i, t}$ follows a process of

$$
Q_{i, t}=(1-a-b) S_{i}+a \varepsilon_{i, t-1}^{*} \varepsilon_{t-1}^{*^{\prime}}+b Q_{i, t-1}
$$

with $S_{i}$ being an intercept matrix (unconditional covariance of standardised disturbances), a and $\mathrm{b}$ are scalars, $\varepsilon_{i, t-1}^{*}$ is a standardized residual with unit variance as follows:

$$
\varepsilon_{i, t-1}^{*}=r_{i, t-1} / \sigma_{i, t-1}
$$

$\varepsilon_{i, t}^{*}=\varepsilon_{i, t} Q_{i, t-1}^{*}$ with $Q_{i, t}^{*}=\operatorname{diag}\left(Q_{i, t}\right)^{1 / 2}$ where $\operatorname{diag}\left(Q_{i, t}\right)$ is the $(2 \times 2)$ matrix with the diagonal of $Q_{i, t}$ on the diagonal and zeros off-diagonal. $Q_{i, t}$ is an exponentially weighted moving average of past outer products of the standardised returns and is a positive definite matrix under $a>0, b>0, a+b<1$ and the positive definitiveness of $S_{i}$ (unconditional correlation) conditions (Engle \& Mezrich, 1996). The conditional correlations are time-varying and follow a similar structure to a $\operatorname{GARCH}(1,1)$ model. The matrix $S_{i}$ is estimated by

$$
\widehat{S_{l}}=\frac{1}{T} \sum_{t=1}^{T} \varepsilon_{i, t}^{*} \varepsilon_{i, t}^{*^{\prime}}
$$

Given the conditional volatilities and correlations, with the threshold value C, the MES is represented at date $\mathrm{t}$ as;

$$
\begin{aligned}
& \operatorname{MES}_{i, t}(C)=E_{t-1}\left[r_{i, t} \mid r_{m, t}<C\right] \\
& =\sigma_{i, t} E_{t-1}\left[\rho_{i, t} \varepsilon_{m, t}+\sqrt{1-\rho_{i, t}^{2}} \eta_{i, t} \mid \varepsilon_{m, t}<\frac{C}{\sigma_{m, t}}\right] \\
& =\sigma_{i, t} \rho_{i, t} E_{t-1}\left[\varepsilon_{m, t} \mid \varepsilon_{m, t}<\frac{C}{\sigma_{m, t}}\right]+\sigma_{i, t} \sqrt{1-\rho_{i, t}^{2}} E_{t-1}\left[\eta_{i, t} \mid \varepsilon_{m, t}<\frac{C}{\sigma_{m, t}}\right] \\
& =\sigma_{i, t} \rho_{i, t} E_{t-1}\left[\varepsilon_{m, t} \mid \varepsilon_{m, t}<\frac{C}{\sigma_{m, t}}\right]
\end{aligned}
$$

That is why $\varepsilon_{m, t}$ and $\eta_{i, t}$ are supposed to be independent the fourth equality is employed. In this case, in order to calculate MES the distribution of $\varepsilon_{m, t}$ requires to be specified. The model used in this paper takes into account the fat tails observed in equity returns ${ }^{3}$ in order to improve the empirical distribution. That is, $\left\{\widehat{\varepsilon_{m, t}}\right\}$ from the consequence of the DCC estimate, and conduct the following Monte Carlo integration to compute the conditional expectation in the last line of the equation above:

$$
E_{t-1}\left[\varepsilon_{m, t} \mid \varepsilon_{m, t}<\frac{C-\mu_{m, t}}{\sigma_{m, t}}\right] \approx \frac{1}{T} \sum_{t=1}^{T} \widehat{\varepsilon_{m, t}} I\left[\widehat{\varepsilon_{m, t}}<\frac{C-\mu_{m, t}}{\sigma_{m, t}}\right]
$$


Where $I[$.$] is an indicator function that takes 1$ if the argument is true and otherwise it postulates zero.

\subsection{Conditional Value at Risk (CoVaR)}

This paper adopts the CoVaR measure on the basis of the proposition by Girardi and Ergun (2013). Firstly, the value-at-risk of a bank is outlined by Girardi and Ergun (2013) as $\mathrm{i}\left(\operatorname{VaR}_{q, t}^{i}\right)$ as the $q$-th quantile of the return distribution, given the returns $r_{i, t}$ of an institution $i$ and the confidence level $q$;

$$
\operatorname{Pr}\left(r_{i, t} \leq \operatorname{VaR}_{q, t}^{i}\right)=q
$$

For instance, if $q=0.01, \operatorname{VaR}_{0.01, t}^{i}$ is the 1 th quartile of the return distribution. Adrian and Brunnermeier's (2011) define $\operatorname{CoVaR}_{q, t}^{m \mid i}$ as the VaR of an institution $i$ conditional on market being in financial distress, i.e., its return being at its $\operatorname{VaR}$. The $\operatorname{CoVaR}_{q, t}^{m \mid i}$ is implicitly defined by the $q$-quartile of the conditional distribution;

$$
\operatorname{Pr}\left(r_{m, t} \leq \operatorname{CoVaR} R_{q, t}^{m \mid i} \mid r_{i, t} \leq \operatorname{VaR}_{q, t}^{i}\right)=q
$$

The condition part is being less than or equal to bank i's VaR according to its return. The definition of CoVaR is the $q$-th quantile of the market return conditional with respect to conditional part. This definition is different from Adrian and Brunnermeier (2011), they took the condition part as the return is exactly at its VaR.

The systemic risk contribution of an individual bank $i$ is measured as following $\Delta$ CoVaR measure:

$$
\Delta \operatorname{CoVaR}_{q, t}^{m \mid i}=100 \times\left(\operatorname{CoVaR}_{q, t}^{m \mid i}-\operatorname{CoVaR}_{q, t}^{m \mid b^{i}}\right) / \operatorname{CoVaR} R_{q, t}^{m \mid b^{i}}
$$

The $\Delta$ CoVaR is the percentage difference of the VaR of the market where the condition is the bank I which is under distressed situation from the VaR of the market where the condition part is a benchmark state that the conditional standard deviation neighbourhood of the average return as $b^{i} \sim(\mu-\sigma \leq r \leq \mu+\sigma)$. Differently from Adrian and Brunnermeier's (2011), they used the medians as the benchmark state.

As in the computation of the MES measure, the DCC model will also be employed, except the direction of the condition:

$$
\begin{aligned}
& r_{i, t}=\sigma_{i, t} \varepsilon_{i, t} \\
& r_{m, t}=\sigma_{m, t} \rho_{i, t} \varepsilon_{i, t}+\sigma_{m, t} \sqrt{1-\rho_{i, t}^{2} \eta_{m, t}}
\end{aligned}
$$

Here, as in the MES, $\varepsilon_{i, t}$ and $\eta_{m, t}$ are assumed to be independent error terms. In contrast to Girardi and Ergun (2013), the empirical distribution of $\varepsilon_{i, t}$ and $\eta_{m, t}$ is used.

\section{Empirical Results}

\subsection{Data}

After the global financial crisis in 2008, various systemic risk measures have been developed. These measurements are based on market data, which are considered to effectively reflect the information of publicly traded companies. According to Bisias et al. (2012), since the financial system of banks is complex, it is thought that a single measurement system cannot reveal all aspects of systemic risk. Therefore, in this study, the conditional value at risk (CoVaR) measure and the marginal expected shortfall (MES) is applied to the Turkish banking system. MES is a measure of the damage of an organization in the loss distribution of the 
system. CoVaR is based on the concept of Value-at-Risk, denoted VaR, which is the maximum dollar loss within the \%-confidence interval (Jorion, 2007).

Among Turkish banks, the six banks whose stocks are listed on the Borsa Istanbul with resulting Akbank, Finansbank, Garanti Bank, Is Bank, Commercial Bank of China Limited and YapıKredi Bank. Since the daily frequency data are simultaneously available during the period of 2000 through 2016 for only these six banks, the measuring systemic risks during this sample period for these banks is studied.

\subsection{Estimation Results of DCC Models}

In order to calculate both the MES and the CoVaR measures, the multivariate GARCH models and DCC models are used Engel (2002). Figure 2 shows the medians of the conditional correlations and conditional volatilities over time. In the top panel, there is remarkable variation over time - ranging from 0.4 to 0.8 . Conditional correlations show an upward trend during periods of financial instability, such as the Turkish domestic (2001), global financial (2008) and euro area fiscal (2011) crises. Meanwhile, there are two sharp jumps in the conditional correlations. One belongs to $2001 \mathrm{crisis}$ and the other one belongs to the first quarter of 2009. Turkey has negative growth rates in the last quarter of $2008(-6.2 \%)$ and the first quarter of $2009(-13.2 \%)$ that has the significant impact of the correlation.

The bottom panel of Figure 1 plots the time series of the median of the conditional volatility of the equity returns of banks. The conditional volatility of a bank will be the most appropriate indicator in order to show the banking prudential regulations for the individual banks without taking into account the financial system as a whole.

Figure 1. Conditional Correlation and Volatility

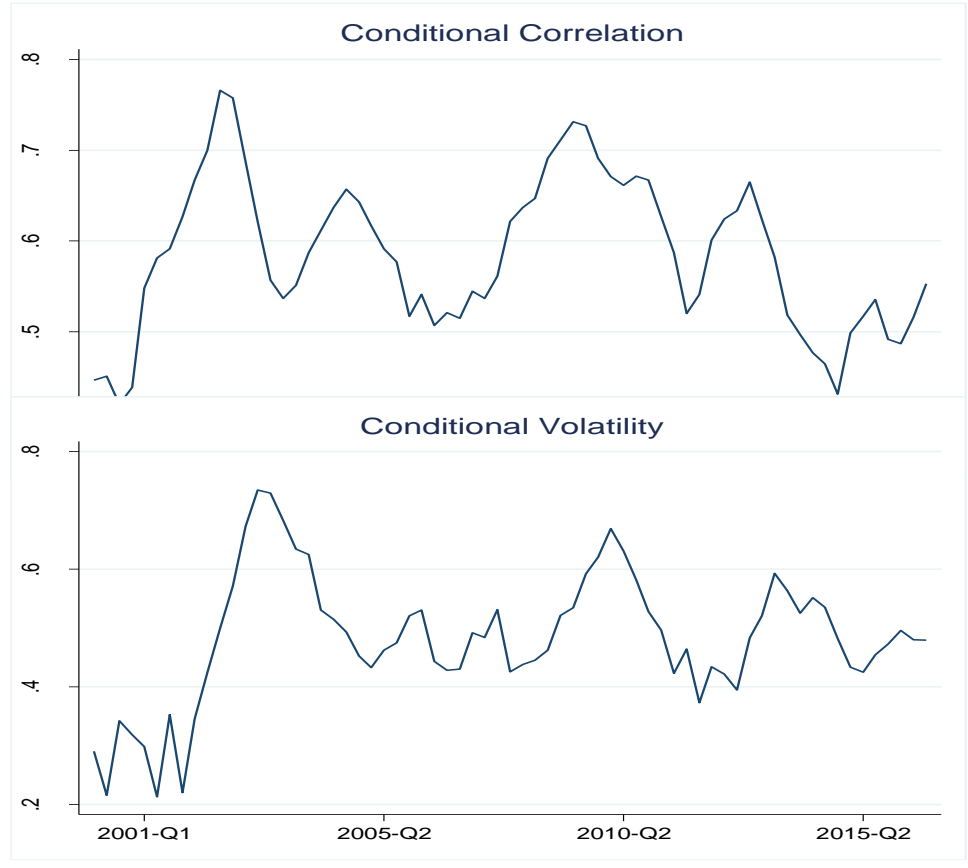

\subsection{Systemic Risk Contributions of Individual Banks}

Using the DCC model, the quarterly MES and $\triangle$ CoVaR measures are estimated for the six banks in Turkey during 2000-2016. In this section, the systemic risk contribution of each individual banks will be stated as well as their rankings. Additionally, the determinants of the systemic risks of banks will be analysed by the panel data estimations.

Table 1 reports the averages of the both systemic risk measures for each bank, and their rankings. According to the table, the result of the both measurement techniques are highly correlated. 
Table 1. Systemic Risk Contributions of Individual Banks

\begin{tabular}{lcccc}
\hline & MES & Rank & $\Delta$ CoVAR & Rank \\
\hline AKBNK & 0.0805 & $(3)$ & 0.8201 & $(4)$ \\
FINBN & 0.1177 & $(1)$ & 0.9479 & $(1)$ \\
GARAN & 0.0333 & $(5)$ & 0.6332 & $(5)$ \\
ICBCT & 0.0863 & $(2)$ & 0.8584 & $(2)$ \\
ISCTR & 0.0150 & $(6)$ & 0.4954 & $(6)$ \\
YKBNK & 0.0606 & $(4)$ & 0.7426 & $(3)$ \\
\hline
\end{tabular}

The scatter diagram between the MES and $\triangle \mathrm{CoVaR}$ is shown as Figure 2. It can be seen that there is very similar way in order to assess each bank's systemic risk contribution. Hence, it seems that the MES and are qualitatively very close for the MES and the $\triangle \mathrm{CoVaR}$ while explaining the differences in cross sectional dimension.

Figure 2. Comparison between MES and $\triangle \mathrm{CoVaR}$

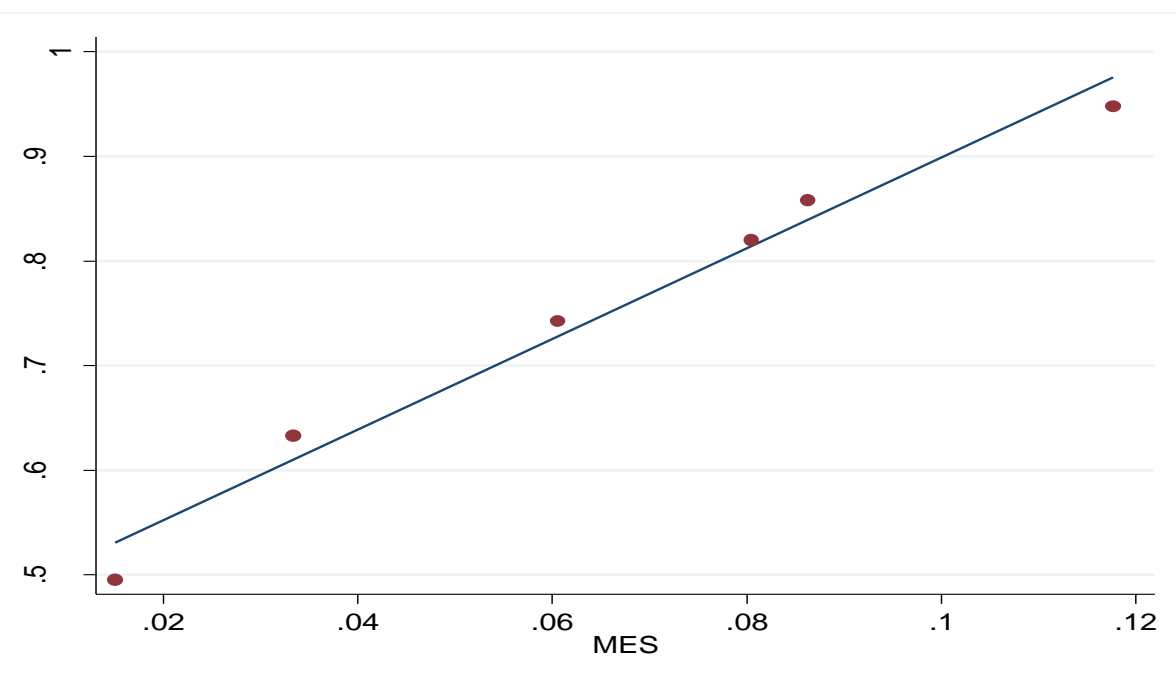

In order to figure out the main determinants of the contributions to systemic risk of individual banks in the time series as well as the cross-sectional dimension, a panel data regression analysis with quarterly data is conducted as stated before. In order to show the effects of the financial market and the macroeconomic environment some related explanatory variables are added. Lagged explanatory variables are conducted in order to eliminate the possible endogeneity problem. The pooled OLS (POLS), a fixed effect (FE) model, a random effect (RE) model and a dynamic panel model (Arellano and Bond, 1991) are employed ${ }^{4}$ in order to cover the robustness of the results.

The first panel data regression is listed in Table 2 which is for the MES. It indicates that except for the dynamic panel model, a lagged VaR has a statistically significant and positive impact on the MES. It is noteworthy that this variable captures the time series effects in the fixed effect model as well as the crosssectional dimension. The findings about this variable contradicts with the literature such as Adrian and Brunnermeier (2011) and Girardi and Ergun (2013).

It is worth to emphasize that the leverage ratio which has positive and significant effect for when all models considered is higher with parallelly as its contribution to systemic risk over time, in time series dimension. In one hand, the log of equity is used as a proxy of the bank size and it slightly affects the systemic risk contribution. On the other hand, in fixed effect and the dynamic panel models, the effects of timeinvariant latent variables lose the effect, it has significant positive coefficient only in the pooled OLS and 
random effect models. The regression has also many variables in order to capture the macro-economic and financial market and it can be concluded that the business cycle is so closely related with the systemic risk contributions of the individual banks.

Table 2. Determinants of MES

\begin{tabular}{|c|c|c|c|c|}
\hline & POLS & $\mathrm{FE}$ & RE & $A B$ \\
\hline \multirow[t]{2}{*}{$\operatorname{VaR}(-1)$} & $0.163^{* * *}$ & $0.196^{* * *}$ & $0.163^{* * *}$ & 1.244 \\
\hline & $(0.0273)$ & $(0.0200)$ & $(0.0271)$ & (1.689) \\
\hline \multirow[t]{2}{*}{ Log equity $(-1)$} & $0.0102^{*}$ & 0.00298 & $0.0102^{*}$ & 0.00145 \\
\hline & $(0.00423)$ & $(0.00793)$ & $(0.00426)$ & $(0.0096)$ \\
\hline \multirow[t]{2}{*}{ Leverage $(-1)$} & $0.0183^{* * *}$ & $0.00228^{*}$ & $0.0183^{* * *}$ & $0.00855^{*}$ \\
\hline & $(0.0017)$ & $(0.00124)$ & $(0.0016)$ & $(0.00511)$ \\
\hline \multirow[t]{2}{*}{ Loan-deposit ratio (-1) } & $-0.0626^{* *}$ & -0.0171 & $-0.0626^{* *}$ & -0.000673 \\
\hline & $(0.0227)$ & $(0.0241)$ & $(0.0223)$ & $(0.00115)$ \\
\hline \multirow[t]{2}{*}{$\operatorname{ROA}(-1)$} & $0.0122^{* * *}$ & $0.00531^{* *}$ & $0.0122^{* * *}$ & $0.00628^{*}$ \\
\hline & $(0.0024)$ & $(0.0019)$ & $(0.0025)$ & (0.00315) \\
\hline \multirow[t]{2}{*}{ GDP growth rate $(-1)$} & $0.00866^{* *}$ & $0.00693^{*}$ & $0.00866^{* *}$ & 0.00530 \\
\hline & $(0.0033)$ & $(0.00296)$ & $(0.0037)$ & $(0.00924)$ \\
\hline \multirow[t]{2}{*}{ Housing index (-1) } & -0.00123 & $-0.0129^{*}$ & -0.00123 & -0.0022 \\
\hline & $(0.0041)$ & $(0.0076)$ & $(0.0041)$ & $(0.0021)$ \\
\hline \multirow[t]{2}{*}{ BIST index return (-1) } & $-0.0678^{*}$ & $-0.0505^{*}$ & $-0.0678^{*}$ & $-0.00995^{*}$ \\
\hline & $(0.0321)$ & $(0.0230)$ & $(0.0328)$ & $(0.00283)$ \\
\hline \multirow[t]{2}{*}{ BIST index volatility (-1) } & $-1.304^{* * *}$ & $-1.099^{* * *}$ & $-1.304^{* * *}$ & $-0.869^{* *}$ \\
\hline & $(0.374)$ & $(0.268)$ & $(0.371)$ & $(0.325)$ \\
\hline \multirow[t]{2}{*}{ TL/Dollar FX return (-1) } & $0.153^{*}$ & $0.149^{*}$ & $0.153^{*}$ & $0.136^{*}$ \\
\hline & $(0.073)$ & $(0.068)$ & $(0.074)$ & $(0.069)$ \\
\hline \multirow[t]{2}{*}{ TL/Dollar FX volatility (-1) } & $-1.532^{*}$ & $-1.401^{* *}$ & $-1.532^{*}$ & $-0.983^{*}$ \\
\hline & $(0.739)$ & $(0.533)$ & $(0.735)$ & $(0.439)$ \\
\hline \multirow[t]{2}{*}{ MES $(-1)$} & - & - & - & $0.4894^{* * *}$ \\
\hline & & & & $(0.056)$ \\
\hline \multirow[t]{2}{*}{ Constant } & $-0.175^{* *}$ & $-0.143^{*}$ & $-0.175^{* *}$ & - \\
\hline & $(0.0612)$ & $(0.0677)$ & $(0.0612)$ & \\
\hline Observations & 396 & 396 & 396 & 396 \\
\hline$R^{2}$ & 0.577 & 0.422 & & \\
\hline
\end{tabular}

POLS, FE, RE and AB stand for pooled OLS, a fixed effect model, a random effect model and a dynamic panel model (Arellano and Bond, 1991), respectively. Standard errors are in parentheses. Explanatory variables listed in the table are lagged by one quarter. The explanatory variables are VaR, log of equity, leverage ratio, loan-deposit ratio, return on assets, GDP, BIST, foreign exchange rate, volatility of foreign exchange rate, volatility of BIS and housing index. ${ }^{*} p<0.05,{ }^{* *} p<0.01,{ }^{* * *} p<0.001$

Table 3. Determinants of $\Delta$ CoVaR

\begin{tabular}{lllll}
\hline & POLS & $\mathrm{FE}$ & $\mathrm{RE}$ & $\mathrm{AB}$ \\
\hline $\operatorname{VaR}(-1)$ & $0.458^{*}$ & $0.564^{* *}$ & $0.458^{*}$ & 0.789 \\
& $(0.226)$ & $(0.217)$ & $(0.226)$ & $(0.578)$ \\
\hline Log equity (-1) & -0.149 & -1.097 & -0.149 & -0.662 \\
& $(0.191)$ & $(0.779)$ & $(0.188)$ & $(0.489)$ \\
\hline Leverage (-1) & $0.209^{* *}$ & 0.135 & $0.209^{* *}$ & 2.433 \\
& $(0.0752)$ & $(0.0748)$ & $(0.0746)$ & $(2.855)$ \\
\hline
\end{tabular}


Measuring Systemic Risks in the Turkish Banking Sector

\begin{tabular}{|c|c|c|c|c|}
\hline Loan-deposit ratio (-1) & $\begin{array}{l}-0.00987 \\
(0.0104)\end{array}$ & $\begin{array}{l}-0.0199 \\
(0.0146)\end{array}$ & $\begin{array}{l}-0.00987 \\
(0.0101)\end{array}$ & $\begin{array}{l}-0.314 \\
(0.349)\end{array}$ \\
\hline \multirow[t]{2}{*}{$\operatorname{ROA}(-1)$} & $0.329^{* *}$ & 0.226 & $0.329^{* *}$ & 2.96 \\
\hline & $(0.111)$ & $(0.115)$ & $(0.117)$ & $(3.35)$ \\
\hline \multirow[t]{2}{*}{ GDP growth rate $(-1)$} & $0.524^{* *}$ & $0.395^{*}$ & $0.524^{* *}$ & $1.918^{* *}$ \\
\hline & (0.189) & $(0.189)$ & $(0.186)$ & $(0.798)$ \\
\hline \multirow[t]{2}{*}{ Housing index (-1) } & -0.163 & -0.308 & -0.163 & -0.844 \\
\hline & $(0.182)$ & $(0.183)$ & $(0.188)$ & $(1.241)$ \\
\hline \multirow[t]{2}{*}{ BIST index return $(-1)$} & -1.120 & -0.486 & -1.120 & -0.723 \\
\hline & $(1.667)$ & $(1.642)$ & $(1.676)$ & $(1.056)$ \\
\hline \multirow[t]{2}{*}{ BIST index volatility $(-1)$} & -14.22 & -14.54 & -14.22 & -9.874 \\
\hline & $(16.85)$ & (16.29) & $(16.76)$ & $(12.764)$ \\
\hline \multirow[t]{2}{*}{ TL/Dollar FX return $(-1)$} & -1.235 & 0.509 & -1.235 & 0.956 \\
\hline & (4.263) & $(4.166)$ & (4.268) & $(2.568)$ \\
\hline \multirow[t]{2}{*}{ TL/Dollar FX volatility $(-1)$} & 4.966 & 4.695 & 4.966 & 2.846 \\
\hline & $(33.24)$ & $(32.38)$ & $(33.24)$ & $(24.85)$ \\
\hline \multirow[t]{2}{*}{$\Delta \operatorname{CoVaR}(-1)$} & - & - & - & $0.363^{* * *}$ \\
\hline & & & & $(0.072)$ \\
\hline \multirow[t]{2}{*}{ Constant } & $-3.352^{*}$ & $12.50^{* *}$ & $-3.352^{*}$ & - \\
\hline & $(1.361)$ & $(4.067)$ & $(1.361)$ & \\
\hline Observations & 396 & 396 & 396 & 396 \\
\hline$R^{2}$ & 0.278 & 0.183 & & \\
\hline \multicolumn{5}{|c|}{$\begin{array}{l}\text { POLS, FE, RE and AB stand for pooled OLS, a fixed effect model, a random effect model and a dynamic panel } \\
\text { model (Arellano and Bond, 1991), respectively. Standard errors are in parentheses. Explanatory variables } \\
\text { listed in the table are lagged by one quarter. The explanatory variables are VaR, log of equity, leverage ratio, } \\
\text { loan-deposit ratio, return on assets, GDP, BIST, foreign exchange rate, volatility of foreign exchange rate, } \\
\text { volatility of BIS and housing index. }{ }^{*} p<0.05,{ }^{* *} p<0.01,{ }^{* * *} p<0.001\end{array}$} \\
\hline
\end{tabular}

The determinants of the $\triangle \mathrm{CoVaR}$ measure are reported in Table 3 . The results are very similar with the results for MES in a weaker dimension. It should be importantly underlined that while according to the results of Adrian and Brunnermeier (2011), there is a weak relation between VaR and $\triangle$ CoVaR in the crosssection but it is very strong in the time-series whereas in the results of this paper, there is a weak relation between $\operatorname{VaR}$ and $\triangle \mathrm{CoVaR}$ in the both time-series and cross-section. Furthermore, there are no significant macroeconomic variables in the analysis of $\triangle \mathrm{CoVaR}$ compares to MES. Additionally, in both analyses, there is positive and significant coefficients for the lagged GDP growth rate.

In order to make a reasonable economic interpretation according to the results of the systemic risk measurement, one feature of MES is very helpful. The MES results can be aggregated across banks whereas $\triangle \mathrm{CoVaR}$ cannot. By the help of the additivity feature of MES, the crises are distinguishable from each other. To calculate the aggregate MES, the weighted average results for each bank are used where the weights are taken as proportional to the equities of the banks. 
Figure 3. Aggregate MES

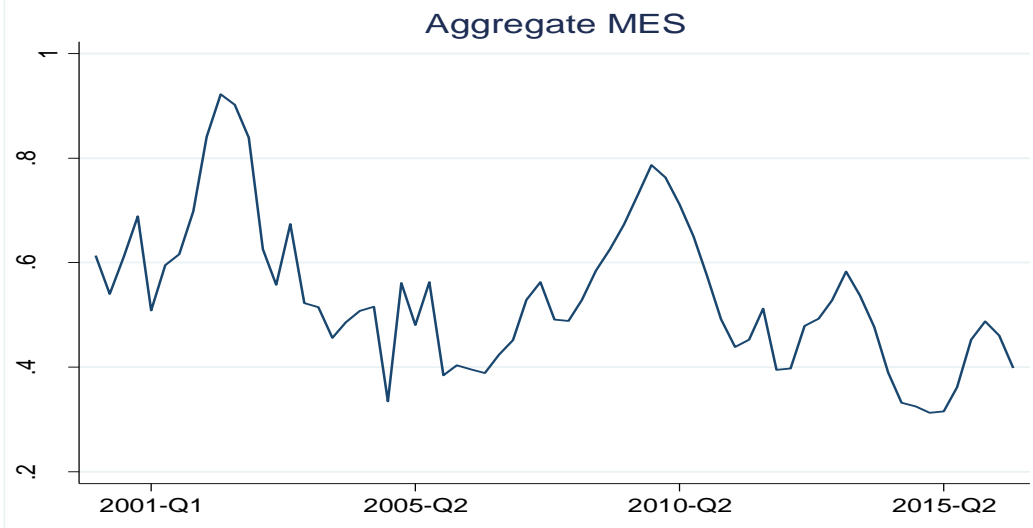

This chart demonstrates the weighted average MES over the period from 2000-Q1 to 2016-Q4 for a sample of six Turkish banks for which this research has access to thorough balance-sheet data. At the first sight the weighted average MES endorses that this method works out relevantly in determining the major global and domestic financial cycles and their effects on Turkish banking industry which enables it pertinently estimating the exposure of given banks to systemic risk.

Stimulatingly, the aggregate MES graphic exhibited that the changing circumstances two years before the 2007-2008 global crisis were obviously signalled by a sharply decreasing average MES. Similarly, in association with the effects of interest rate policy changes implemented by FED and ECB in the context of emerging economies in terms of the volatility of capital flows and the quality of funding and their reflections in Turkish economy from the late 2015 can be tracked by the graph simultaneously. The efforts of CBRT to discourage individual banks to undertake excessive leverage at the beginning 2012 resulted in unexpected reductions in stock volatilities of banks and decrease in their profitability.

Moreover, the measures taken by CBRT to cooldown the domestic credit growth consistently increasing since the beginning of 2000 s by increasing the minimum liquidity ratios to $3 \%$ and capital adequacy ratios to $8 \%$ have negatively affected the business cycles of banks and increased their dependency on equity capital. Note that our application of MES Model takes financial market variables such as log equity, leverage, loan-deposit ratio, ROA, into consideration as well a macro variables such as GDP growth rate, housing index, BIST index return \& volatility, TL/Dollar FX return to estimate systemic risk contributions of individual banks. This phase between 2012 and 2015 exposes certain vulnerabilities of Turkish individual banks both in terms of financial and macroeconomic indicators. Hence the weighted average MES results display that the information revealed by the aggregate MES graphic is consistent with the characteristics that are spontaneously regarded as bases of bank fragility that leads to increasing exposure to systemic risk.

\section{Conclusion}

This article analysed the impacts of regulations on systemic risks in Turkish banking sector by measuring the quarterly MES and $\triangle \mathrm{CoVaR}$ values of six banks in Turkish banking sector. Literature in this field suggests that the major focus of the regulative actions have been to safeguard against the distress of SIFls or to mitigate the systemic impact of their failure. In order to maintain this issue, this paper, first, evaluated the role of SIFIs in emerging systemic risks and addressed how macro-prudential and micro-prudential regulations are measured to mitigate these risks.

Systemic risk is closely associated with a stable financial system and would be outlined as disruption of risk away from financial institutions that is initiated by a deficiency of any part of financial system and has the propensity to bear serious negative effect the whole economic activities. Turkey's banking system demonstrates compliance with the banking systems in developing countries to with at lower concentration level and exhibits a distant structure compared to the banking systems of developed economies in which 
SIFIs take part a considerably large proportion. In line with this, in recent years, Turkey has been quite successful on implementing many the macro-prudential reforms using a broad range of policies on both individual financial institutions and borrowers. Besides, the implementation and design of these macroprudential reforms have demonstrated their effects over the most vulnerable issues associated with systemic risks in Turkish banking system such as value at risk, liquidity, leverage, loan-deposit ratio and return on asset. Therefore, this study focused on the availability of the banks' data during the period of 2000 through 2016 to measure the impact of banks on systemic risks in Turkish banking sector. To measure the systemic risk, the MES and the CoVaR methods have been employed by using DCC model.

The findings of the analysis carried out in this study can be summed up under three main inferences. First of all, as the two systemic risk measures (eg. CoVaR vs. MES) are critically compared by concentrating on how inversely they appraise an individual bank's contribution to systemic risk. We found that though these measures deliver dissimilar rankings on the systemic risk contributions, qualitatively they appear to be very alike in explanation of the cross-sectional alterations in terms of systemic risk contributions. However, this study is based on the assumption that the aggregate MES can be used as an inclusive systemic risk indicator for the banking system as a whole due to its compatibility with the historical changes in real economy.

Secondly, by using simple panel data regression methods for both of these models, the association between the systemic risk contributions and individual bank specific variables is studied. The results showed that an individual bank's VaR influences that bank's systemic risk contribution both in terms of the time series and the cross-sectional dimensions. This is contrary to the literature where noteworthy links between the systemic risk contribution measures and VaR for US banks could not be found.

Thirdly, the results of this study could not find a close relationship between systemic risk contributions and leverage ratios in the cross-sectional dimension, however rising leverage ratios lead to an increasing systemic risk contribution in the long term. Additionally, the results of showed that there is a weak relationship between the size of a bank and its contribution to systemic risk.

Data utilised in this study is limited to the stock market information in order to assess the systemic risk measures. Yet there may be many valuable data sources such as option prices, CDS premium or other financial and macro variables. Integration of such macro or market data into evaluation of systemic risk measures will be a significant future research topic. Furthermore, most of the policy decisions, including the policy rate determinations of central banks are temporarily carried out on a monthly basis. Similarly, most of the macroeconomic data are released on a weekly or monthly basis. Hence, in terms of data convenience the complete systemic risk measures can be administered by monthly indicators.

In conclusion, we believe that VaR and MES systemic risk measures are informative and useful for Turkish financial institutions. For future studies, we encourage a thorough and systematic risk studies in as many countries as possible. The models, which are studied, will also enable us to examine the similarities and differences between different systemic risk measurements. Therefore, further research should be done to find the most appropriate macroeconomic factors that may affect systemic risk assessment in terms of volatility and correlation modelling.

\section{End Notes}

1. This study presented as an oral presentation in ICOAEF' 19 International Conference on Applied Economics and Finance \& Extended with Social Science, April 09 to 11, 2019, Kyrenia/North Cyprus, and also this written version is extended of the presented one.

2. Brownlees and Engle (2012) assume that $\varepsilon_{-} m t$ and $\eta_{-}$it have zero correlation but no independence. Hence, they allow tail dependence.

3. Differently from this paper, Brownlees and Engle (2012) use a nonparametric kernel estimation approach. 
4. Among the pooled OLS, fixed effect and random effect models, the results of the F test, the Breusch and Pagan test (1980), the Hausman (1978) test and the Sargan (1985) are found and the fixed effect model is the most appropriate one.

\section{References}

Adrian, T., \& Brunnermeier, M. K. (2011). CoVaR. NBER Working Paper, No 17454.

Bisias, D., Flood, M., Lo, A. W., \& Valavanis, S. (2012). A survey of systemic risk analytics. Annual Review of Financial Economics, 4, 255-296.

Brownlees, T. C., \& Engle, R. (2012). Volatility, correlation and tails for systemic risk measurement. Working Paper, NYU.

Bullard, J., Neely, C., \& Wheelock, D. (2009). Systemic risk and the financial crisis: A primer. Federal Reserve Bank St. Louis Review, 91(5, part 1), 403-417.

Cihak, M., Munoz, S., Sharifuddin, S. T., \& Tintchev, K. (2012). Financial stability reports: What are they good for? IMF Working Paper 12/1, Washington.

Ciro, T. (2012). The global financial crisis: Triggers, responses and aftermath. Ashgate Publishing Company, Burlington, VT.

Claessens, S., \& Kodres, L. (2014). The regulatory responses to the global financial crisis: Some uncomfortable questions. IMF Working Paper, WP/14/46: 1-39.

De Jonghe, O. (2010). Back to the basics in banking? A micro-analysis of banking system stability. Journal of Financial Intermediation, 19(3), 387-437.

Derbali A., \& Hallara S. (2016). Systemic risk of European institutions: Estimation and ranking by Marginal Expected Shortfall. Research in International Business and Finance, 37, 113-134.

Engle, R. (2002). Dynamic conditional correlation: A simple class of multivariate generalized autoregressive conditional heteroskedasticity models. Journal of Business and Economic Statistics, 20, 339-350.

Engle, R., \& Mezrich, J. (1996). GARCH for groups risk. Risk Magazine, 9, 36-40.

Girardi, G., \& Ergun, A.T. (2013). Systemic risk measurement: Multivariate GARCH estimation of CoVaR. Journal of Banking and Finance, 37, 3169-3180.

Glosten, L. R., Jaganathan, R., \& Runkle, D. E. (1993). On the relation between the expected value and the volatility of the nominal excess return on stocks. Journal of Finance, 48, 1779-1801.

Guntay, L., \& Kupiec, P. (2014). Taking the risk out of systemic risk measurement. American Enterprise Institute, Working Paper

Huang, Q., De Haan, J., \& Scholtens, B. (2017). Analysing systemic risk in the Chinese banking system. Pacific Economic Review, doi:10.1111/ 1468-0106.12212.

Jorion, P. (2007) Value at Risk: The new benchmark for managing financial risk (3rd ed.) McGrawHill.

Mishkin, F. (1995). Comment on systemic risk. In G. Kaufman (Ed.), Research in Financial Services: Banking, Financial Markets, and Systemic Risk, Vol. 7 (pp.31-45), Greenwich: JAI Press.

Reavis, C. (2012). The global financial crisis of 2008: The role of greed, fear, and oligarchs. MIT Sloan School of Management, Review No: 09-093.

Seccareccia, M. (2012). Financialization and the transformation of commercial banking: Understanding the recent Canadian experience before and during the international financial crisis. Journal of Post Keynesian Economics, 35(2), 277-300.

Seibt, C. H., \& Schwarz, S. (2011). European financial market regulation in the wake of the financial crisis: A functional approach. China-EU Law Journal, 1, 95-118.

Stiroh, K., \& Rumble, A. (2006). The dark side of diversification: The case of US financial holding companies. Journal of Banking and Finance, 30(8), 2131-2161.

Stiroh, K. (2006). A portfolio view of banking with interest and noninterest activities. Journal of Money, Credit and Banking, 38(5), 1351-1361.

Stöhr, A. (2015). Approaches to financial regulation in view of the crisis. Journal of Financial Regulation and Compliance, 23(1), 73-83. 
Talaslı, I. (2013). Systemic risk analysis of Turkish financial institutions with systemic expected shortfall. Central Bank Review, 13, 25-40.

Tian, W. (2017). Commercial banking risk management: Regulation in the wake of the financial crisis. New York: Palgrave Macmillan.

Wagner, W. (2010). Diversification at financial institutions and systemic crises. Journal of Financial Intermediation, 19(3), 373-386. 